\title{
ENVIRONMENTAL IMPACT OF WATER TREATMENT PROCESS. A SYSTEMATIC REVIEW OF EVALUATION METHOD
}

\author{
FLORINA FABIAN ${ }^{1 *}$, VALENTIN NEDEFF ${ }^{1}$, MIRELA PANAINTE - LEHADUS ${ }^{1}$, \\ NARCIS BÂRSAN ${ }^{1}$, OANA IRIMIA ${ }^{1}$, SILVIA RACOVITA ${ }^{2}$ \\ ${ }^{I}$ Department of Environmental Engineering and Mechanical Engineering, ,, Vasile \\ Alecsandri" University of Bacău, Street Mărăşsesti 157- 600115, Bacău, România \\ ${ }^{2}$ Moldova State University, Street A. Mateevici 60 - 2009, Chisinau, Republic of Moldova
}

\begin{abstract}
In an international context in continuous development, water treatment processes become an important component of society where we live. Attention is directed on water treatment processes in the context of increasing water demand. This study proposes a systematic review of methods for the assessment of the environmental impact of Water Treatment process. The approach is based on the evaluation of LCA, Externalities Evaluation methodology and Carbon Footprint methodology, each of these methods have the environmental indicators able to relate direct and indirect emissions generated by any water treatment process. The present review compares and discusses the implementation of the above-cited methodologies to different case studies. The results in short show that Carbon Footprint only assesses the global warming potential of a water treatment plant, whereas Life Cycle Analysis and assess multiple environmental impact categories, which may include global warming, but also impacts on human health, ecosystems quality, etc. There are different standards and organizations around each assessment. The ExternE method on the contrary aims to quantify external impacts, from both economic and social points of view, to weight each endpoint of the impact categories.
\end{abstract}

Keywords: water treatment, environmental impact, methods for the assessment

\section{INTRODUCTION}

Water is one of the most precious natural resources which has been the subject of ever increasing environmental impacts, as a consequence of its continuous exploitation for meeting the human needs, for economic and social development and those due to climate change. The impact of the climate changes and the increased environmental pollution at the present time require a deeper study not only the efficiency of the water treatment process but also of its environmental impact through diversified approaches [1, 2].

The traditional tools of evaluation of water treatment plants concern the efficiency in removal of critical parameters and the evaluation of cost for operative activities. They must be today integrated with a verification of the total compatibility of the process; in account of the large effect of this aspect, in particular the capacity to generate GHG from energy use and from chemicals transport and utilization must be carefully considered.

To this aim, the well consolidated definition of energy and materials balance for a water treatment plant must be completed with the specific environmental load, in terms of carbon footprint, of the different fluxes, in order to define a general numerical parameter of estimation for the evaluation of compatibility.

\footnotetext{
* Corresponding author, email: florina.fabian@yahoo.com;

(c) 2016 Alma Mater Publishing House
} 
Climate change is a characteristic of our planet's history. Earth has suffered in its history a series of major changes in climate and now we are in a process of gradual warming. It should be noted that the greenhouse effect of gases in the atmosphere is essential for life to exist on Earth [3-7].

If we refer to making water drinkable, this process means removing most of the organic components, inorganic and biological components found in water, resulting water which satisfies national and international standards concerning drinkable water. Europe consumes from its own main water resource, also Europe is not a dry continent, but water supplies are currently a factor of concern for at least half of the EU population [7].

IPCC (Intergovernmental Panel for Climate Change) defined Global warming Potential (GWP) factors to evaluate the emissions related to each GHG as $\mathrm{CO} 2$ equivalents, taking into account a period equal to 100 years (see Table 1). The GWP of each GHG should be multiplied with its average concentration value in atmosphere to obtain the specific 'participation shares' [7-9].

Table 1.Greenhouse Gases, Global Warming Potentials and sources of production [7].

\begin{tabular}{|c|c|c|}
\hline GHG & $\begin{array}{c}\text { Global } \\
\text { Warming } \\
\text { Potential } \\
\end{array}$ & Main sources of production \\
\hline Carbon dioxide $\left(\mathrm{CO}_{2}\right)$ & 1 & $\begin{array}{l}\text { combustion processes, heat generation, concrete } \\
\text { production, deforestation }\end{array}$ \\
\hline Methane $\left(\mathrm{CH}_{4}\right)$ & 25 & $\begin{array}{l}\text { rice cultivation, fossile fuels mining, landfills, } \\
\text { anaerobic degradation processes }\end{array}$ \\
\hline Nitrous oxide $\left(\mathrm{N}_{2} \mathrm{O}\right)$ & 298 & $\begin{array}{l}\text { agriculture, combustion processes, } \\
\text { Production and adipic acid nitric } \\
\text { Water treatment } \\
\text { Combustion processes }\end{array}$ \\
\hline $\begin{array}{l}\text { Hydrofluorocarbons (HFCs) } \\
\text { Hydrochlorofluorocarbons (HCFCs) }\end{array}$ & $77-14800$ & Refrigeration systems \\
\hline Perfluorocarbons (PFCs) & $7390-17700$ & $\begin{array}{l}\text { Refrigeration systems } \\
\text { Production of aluminum and magnesium }\end{array}$ \\
\hline Sulphur hexafluoride (SF6) & 22800 & $\begin{array}{l}\text { Production of aluminum and magnesium } \\
\text { Electric high voltage }\end{array}$ \\
\hline
\end{tabular}

\section{ENVIRONMENTAL ASSESSMENT BY MEANS OF SEVERAL APPROACHES}

Efficiency of water treatment process involves an in depth study, by using various methodological approaches and here I refer to Life Cycle Assessment (LCA), Carbon Footprint methodology and the Externalities Evaluation methodology. These approaches require the knowledge of each equipment in the water treatment, their energy consumption, material flows (quantity of chemicals) and also from where are the chemicals transported to the plant and in the final their transformation into a common unit of measurement which is $\mathrm{CO}_{2} \mathrm{eq}$.

\subsection{Life cycle assessment $-\mathrm{LCA}$}

In ISO 14040 LCA is defined as the "compilation and evaluation of the inputs, outputs and potential environmental impacts of a product system throughout its life cycle". The total system of unit processes involved in the life cycle of a product is called the "product system". The main applications of LCA are in [10]:

$\checkmark$ analysing the origins of problems related to a particular product;

$\checkmark$ comparing improvement variants of a given product;

$\checkmark$ designing new products;

$\checkmark$ choosing between a number of comparable products.

The environmental burden covers all types of impacts upon the environment, including extraction of different types of resources, emission of hazardous substances and different types of land use. The term 'product' is taken in its broadest sense - including physical goods as well as services; it includes goods and services at both operational and strategic levels. It is important to note that in comparative LCA studies, it is not the products themselves that form the basis for the comparison, but the function provided by these products. LCA is, as far as 
possible, quantitative in character; where it is not possible, qualitative aspects can - and should - be taken into account, and are given the environmental impacts involved [10].

Similar applications can be distinguished at a strategic level, dealing with government policies and business strategies. The way an LCA project is implemented depends on the intended use of the LCA results.

\subsection{Carbon Footprints methodology}

Carbon footprint is the cumulative effect of various human activities on the environment of the Earth. It is estimated on the grounds of the methodology established by ISO 14040: 2006, Life Cycle Assessment: Principles and Framework and ISO 14044: 2006, Life Cycle Assessment: requirements and guidelines, and Publicly Available Specification (PAS 2050) [6].

An analysis of the life cycle of the considered product, with a detailed definition of all the involved processes, is necessary to detect all direct and indirect emissions sources. The standard is explicit about this issue: "An inventory consists of service, material and energy flows that become the product, make the product, and carry the product through its life cycle. These are defined as attributable processes" [7]. They may be listed as follows [7]:

- Capital goods (e.g., machinery, trucks, infrastructures);

- Overhead operations (e.g., facility lighting, air conditioning);

- Corporate activities and services (e.g., research and development, administrative functions, company sales and marketing);

- Transport of the product user to the retail location;

- Transport of employees to and from works.

The most important step for applying the methodology of Carbon Footprint is computation. As it follows, we can quantify the data that we have using GWPs values provided by IPCC to turn them in the unit that interests us, namely $\mathrm{CO}_{2}$ equivalent:

$$
\begin{gathered}
\mathrm{kgCO}_{2} \mathrm{e}=\text { Direct Emissions Data }[\mathrm{kg} \mathrm{GHG}] \times \mathrm{GWP}\left[\frac{\mathrm{kgCO} \mathrm{e}}{\mathrm{kgGES}}\right] \\
\left.\mathrm{kgCO}_{2} \mathrm{e}=\text { Activity Data [unit of measure }\right] \times \text { Emission Factor }\left[\frac{\mathrm{kg} \mathrm{GHG}}{\text { unit of measure }}\right] \times \text { GWP }\left[\frac{\mathrm{kg} \mathrm{CO} 2 \mathrm{e}}{\mathrm{kg} \mathrm{GHG}}\right]
\end{gathered}
$$

Therefore calculation of the Carbon Footprint should take into account reference flow so that the amount obtained to be fairly and justifiable [10-11]:

$$
\begin{aligned}
& \frac{\text { Total CO2 }}{\text { Unit of analysis }}=\frac{\text { CO2e Emissions (biogenic) }}{\text { reference flow }}-\frac{\text { CO2e Removals(Biogenic) }}{\text { reference flow }}+ \\
& \qquad \begin{array}{l}
\text { CO2e Emissions (Non-Biogenic) } \\
\text { reference flow }
\end{array}-\frac{\text { CO2e Removals (Non-Biogenic) }}{\text { reference flow }}+\frac{\text { CO2e Land Use Change Impacts }}{\text { reference flow }}
\end{aligned}
$$

The total $\mathrm{CO}_{2}$ eq/unit of analysis represents the amount of $\mathrm{CO}_{2}$ equivalent $\mathrm{GHG}$ entering the atmosphere as a result of fulfilling the function of a product. Therefore, in the mass balance, emissions are treated as positive values and removals are treated as negative values. Land-use change impacts are included in the total inventory results if they are attributable to the studied product. If no land-use change impacts are attributable and no removals occur during the product's life cycle, the total inventory results are simply the sum of emissions in $\mathrm{CO}_{2}$ equivalent per reference flow 76].

\subsection{Externalities Evaluation methodology}

According to Griffin and Steele (1986), external costs exist when "the private calculation of benefits or costs differs from society's valuation of benefits or costs". Pollution represents an external cost because damages associated with it are borne by society as a whole and are not reflected in market transactions [10].

The ExternE methodology aims to cover all relevant (i.e. not negligible) external effects. However, in the current state of knowledge, there are still gaps and uncertainties. The purpose is to cover more effects and thus reduce gaps and in addition to refine the methodology to reduce uncertainties. Currently, the following impact categories are included in the methodology and described in detail, environmental impacts, global warming impacts, accidents, energy security [11]. 
The ExternE methodology provides a framework for transforming impacts that are expressed in different units into a common unit - monetary values. In general, external costs can be crudely characterized by equation [12]:

Externality Cost $=$ Size of Insult $x$ Value of Environmental Damage per unit of insult

where:

Externality Cost are total external cost to society, in dollars;

Size of Insult - expressed in physical units (lbs emitted or hectares degraded);

Value of Environmental Damage (VED) - expressed in dollars per physical unit of insult.

Externality costs must be normalized to some common unit of service for consistent comparison. It should also be noted that to calculate Externalities of Energy for water treatment process it used the equation [12]:

$$
\mathrm{kWh} / \mathrm{m}^{3}+\mathrm{kg} \text { chemicals } / \mathrm{m}^{3}=\mathrm{kgCO}_{2 /} \mathrm{m}^{3}
$$

where:

$\mathrm{kWh} / \mathrm{m}^{3}$ is is the quantity of energy used to produce one $\mathrm{m}^{3}$ of driking water;

$\mathrm{kg}$ chemicals $/ \mathrm{m}^{3}$ - quantity of chemicals used to produce one $\mathrm{m}^{3}$ of driking water;

$\mathrm{kgCO}_{2 /} \mathrm{m}^{3}$ - quantity of $\mathrm{CO}_{2}$ emitted for the production of a one $\mathrm{m}^{3}$ of driking water.

\section{RESULTS AND DISCUSSION}

LCA can play a useful role in public and private environmental management in relation to products. This may involve both an environmental comparison between existing products and the development of new products, which also includes comparisons with prototypes [10].

Another application concerns eco-labeling (i.e. assigning a 'green label' to environmentally friendly product alternatives), enabling consumers to make comparisons between products. Eco-labeling programmes like the EU's are increasingly based on LCA. Up to now, some of these programs have not lived up to their expectations. Positive examples in this area are the Blue Angel eco-labeling program in Germany and the Green Swan eco-label in Scandinavia [10].

Apart from direct product applications, it is also possible to use LCA in a wider sense. Rather than dealing with well-defined physical goods or simple services, LCA is applied here to complex business strategies or government policies relating to consumption and lifestyle choices in various sectors of society. As in the situations described above, it is the function provided which is the core object of the LCA project, but now this function is more complex, more encompassing, and related to strategic decisions. Examples of the wider applications of LCA include [13]:

$\checkmark$ The choice of one-way packaging by an industry. The EU's Packaging Directive allows this, on condition that it can be proved that this creates less of an environmental burden than the use of reusable packaging materials;

$\checkmark$ Comparison between different types of waste management by a municipality, or the development of a waste management strategy;

$\checkmark$ Assessment of the environmental benefits of different types of biomass use (including thinning wood), for instance in the production of electricity or paper;

$\checkmark \quad$ Strategic comparison between different modes of freight transport (road, rail, water) as a basis for public investment in new infrastructure;

$\checkmark \quad$ The 'greening' of the building industry. In the Netherlands, for instance, new houses must in the future meet minimum environmental requirements. In addition to energy consumption, this specifically includes requirements on the environmental burdens imposed by all materials used in the building of a house, to be based upon quantitative LCA.

The difference between the two areas distinguished here, that relating to products and the wider applications, is in fact merely one of degree. For instance, the first and the last example mentioned above, that of the choice for oneway packaging and of LCA in the building industry, offers the potential of 'greening' every aspect of the industries involved. At the same time, it could also be seen as an example of product policy, where the product is unusually large - a whole building [10]. 
In short, carbon footprint only assesses the global warming potential of an organization, product, project or service, whereas a life cycle assessment (LCA) assesses multiple environmental impact categories, which may include global warming, but may also include human health impacts, ecosystem quality, acidification, land use etc. There are different standards and organizations around each assessment [13].

Beyond the number of impact categories examined, carbon footprint separates out the inputs into (1) Scope 1 - all direct GHG emissions associated with owned or controlled activities; (2) Scope 2 - indirect GHG emissions from purchase electricity, heat or steam; and (3) Scope 3 - other indirect emissions such as transport-related activities in vehicles that are not owned by the organization, waste disposal etc. [13], whereas an LCA commonly separates the inputs into life cycle phase (raw material extraction, manufacturing, distribution, use and disposal), regardless of who owns or controls the activity causing the emission [14].

The GHG Protocol standards for carbon footprints are similar to the ISO standards (14040 and 14044) for LCAs in so far as they require that the goal and scope be defined, data collected with the inventory or system boundary, and documentation of assumptions, limitations, conclusions and recommendations in a report. Both require some sort of verification before the report is released to the public, which will provide the reader assurance that the assessment was conducted in a fair and transparent manner [15].

LCA identifies potential impacts, weighted following a 'distance to target' approach, i.e. to which extent current levels of emissions exceed stated policy objectives. The ExternE method on the contrary aims to quantify real impacts, and uses individual preferences (expressed as willingness to pay) to weigh each endpoint of the impact categories. Different analysis shows that it is useful to use both methods to profit from their relative strengths and compensate for the weaknesses in each method. The LCA Eco-indicator approach covers a wide range of ecological impacts and reveals their importance for the different areas of activity [16].

As the external costs analysis does not monetize ecological impacts, it cannot confirm nor contradict these findings. Although there are several attempts to integrate public health into LCA analysis [11].

\section{CONCLUSIONS}

The main objective of this paper was to assess the evaluation methods of environmental impacts for water treatment plant from Romania by using three different impact assessment instruments: (1) life cycle assessment (LCA), (2) carbon footprint methodology and (3) ExternE methodology, compare these three methodologies from a practical and applicability point of view in order to support various water management stakeholders and especially the water treatment operators.

The three methodologies present rather different approaches to environmental impact definition and quantification due to water treatment as it was presented in the overview of methods development and application.

LCA is a core topic in the field of environmental management. Its history goes back to the early seventies, though in the past, it went by different names such as Resource and Environmental Profile Analysis (REPA), Energy Analysis or Product Ecobalance. Here is reviewed the role of a number of international bodies that have been and are - concerned with the development and application of LCA like [16]: SETAC (the Society of Environmental Toxicology and Chemistry), ISO (the International Organization for Standardization), UNEP (the United Nations Environmental Programme).

The carbon footprint of activities and products has become a popular concept, as governments, businesses and individuals are increasingly aware about climate change and concerned about their own impacts on it. But despite media attention and wide public acceptance, its use as a tool to track and reduce greenhouse gas emissions has serious challenges, from its lack of universal guidelines, to ambiguity in policy responses such as offsetting. In the same time ExternE methodology provides a framework for transforming impacts that are expressed in different units into a common unit - monetary values.

The traditional tools of evaluation of water treatment plants concern the efficiency in removal of critical parameters and the evaluation of cost for operative activities. They must be today integrated with a verification of the total 
compatibility of the process; in account of the large effect of this aspect, in particular the capacity to generate GHG from energy use and from chemicals transport and utilization must be carefully considered.

To this aim, the well consolidated definition of energy and materials balance for a water treatment plant must be completed with the specific environmental load, in terms of carbon foot -print, of the different fluxes, in order to define a general numerical parameter of estimation for the evaluation of compatibility.

Carbon footprints carry the potential of being a good entry point for increasing consumer awareness and fostering discussions about the environmental impacts of products. This, in turn, facilities the diffusion of life cycle thinking and LCA. It may even have the potential to promote a more consistent framework for environmental assessment of products and services.

\section{REFERENCES}

[1] Barsan, N., Nedeff, V., Temea, A., Mosnegutu, E., Chitimus, A.D., Tomozei, C., A perspective for poor wastewater infrastructure regions: a small-scale Sequencing Batch Reactor treatment system, Chemistry Journal of Moldova, vol. 12, no. 1, 2017, p. 61-66.

[2] Barsan, N., Nedeff, V., Mosnegutu, E., Panainte, M., Heat balance components of a small Sequencing Batch Reactor applied for municipal wastewater treatment, Environmental Engineering \& Management Journal, vol. 11, no. 12,2012 , p. 2133-2140.

[3] Tirtoaca Irimia, O., Tomozei, C., Panainte, M., Mosnegutu, E.F., Barsan, N., Efficiency of filters with different filtering materials: comparative study in water treatment, Environmental Engineering \& Management Journal, vol. 11, no. 12, 2012, p. 2133-2140.

[4] Capşa, D., Barsan, N., Felegeanu, D., Stanila, M., Joita, I., Rotaru, M., Camelia, U. Influence of climatic factors on the pollution with nitrogen oxides (NOX) in Bacau City, Romania, Environmental Engineering \& Management Journal, vol. 15, no. 3, 2016, p. 655-663.

[5] Capșa, D., Bârsan, N., Nedeff, V., Moșneguțu, E., Chițimuş, D., Evaluation of the ammonia air pollution and climatic factors interactions, case study 2008 Bacau City Romania, Journal of Engineering Studies and Research, vol. 22, no. 1, 2016, p. 24-31.

[6] Course about: Climate change and their effects on soil. Economic activities that generate greenhouse gas emissions, 2010, p 1-5. Available at: http://www.eco-research.eu/CURS\%2010\%20ECO.pdf, (17/8/2015).

[7] Pankaj, B., Brown, A., World resources institute, World business council for sustainable development, greenhouse gas protocol, Product life cycle accounting and reporting standard, vol. 1, 2011, p. 18-20.

[8] European Commision 'Water scarcity and droughts in the European Union', August 2010. Available at: http://ec.europa.eu/environment/pubs/pdf/factsheets/water_scarcity/it.pdf, (27/8/2015).

[9] Igos, E., Benetto, E., Baudin, I., Tiruta-Barna, L., Mery, Y., Arbault, D., Cost-performance indicator for comparative environmental assessment of water treatment plants, Science of the Total Environment, vol. 443, 2013, p. 367-374.

[10] Kluwer Academic Publishers, 'Handbook on Life Cycle Assessment', United States of America, vol.7, 2002.

[11] Koomey, J., Krause, F., Introduction to environmental externality costs, CRC Handbook on Energy Efficiency, USA, 1997.

[12] Merenda, A., Rovero, G., Applicazione della metodologia carbon footprint agli impianti di potabilizzazione, Torino, Italy, 2012.

[13] http://www.ghgprotocol.org/, (25/8/2015).

[14] Bickel P., Friedrich R., Externalities of energy, methodology, Update, European Commission, Stuttgart, Germany, 2005. Available at: http://ec.europa.eu/research/energy/pdf/kina_en.pdf (07/8/2015).

[15] http://www.ghgprotocol.org/calculation-tools/faq, (25/8/2015).

[16] http://aoatools.aua.gr/pilotec/files/bibliography/biodiesel_excost_default-4179801601/ biodiesel_ excost_ default.pdf $(25 / 8 / 2015)$. 